\title{
Quo vadis, biological treatment for psoriasis and psoriatic arthritis?
}

\author{
Barbara Olszewska, Zygmunt Adamski, Magdalena Czarnecka-Operacz
}

Department of Dermatology, Poznan University of Medical Sciences, Poznan, Poland

Adv Dermatol Allergol 2018; XXXV (3): 231-237

DOI: https://doi.org/10.5114/ada.2018.76086

\begin{abstract}
Psoriasis is a chronic autoimmune disease that affects approximately $2-3 \%$ of the world's population. Although the cutaneous manifestations of the disease are the most prevalent, psoriasis is also associated with a systemic inflammation and various co-morbidities linked with autoinflammatory processes. One of those processes is psoriatic arthritis, an inflammatory, seronegative spondyloarthropathy that develops in $13.8-30 \%$ of psoriatic patients at some point of their lives. Over the past 15 years the therapeutic options for severe and generalized psoriasis have broadened immensely with the introduction of biological agents to everyday practice. We present a quick overview of current biological therapies in the treatment of psoriasis and prospects for forthcoming advancements in biological treatment.
\end{abstract}

Key words: psoriasis, biological treatment, biologics, psoriatic arthritis.

\section{Introduction}

Psoriasis is a chronic autoimmune disease that affects approximately $2-3 \%$ of the world's population [1]. Although the cutaneous manifestations of the disease are the most prevalent, psoriasis is also associated with a systemic inflammation and various co-morbidities linked with autoinflammatory processes [2]. One of those processes is psoriatic arthritis (PSA), an inflammatory, seronegative spondyloarthropathy that develops in 13.8$30 \%$ of psoriatic patients at some point of their lives [3, 4]. Over the past 15 years the therapeutic options for severe and generalized psoriasis have broadened immensely with the introduction of biological agents to everyday practice. We present a quick overview of current biological therapies in the treatment of psoriasis and prospects for forthcoming advancements in biological treatment.

\section{Pathogenesis of psoriasis}

The complex pathophysiology that underlies mechanisms leading to abnormal keratinocyte differentiation, and subsequently, development of psoriatic lesions, is still not fully known. Aberrations of more than 2000 genes located on 15 chromosomes have already been identified to play fundamental roles in the pathogenesis of psoriasis [5]. The underlying condition leads to uncon- trolled proliferation of basal keratinocytes and inhibited terminal differentiation of suprabasal keratinocytes a process that takes about 4-6 weeks in uninvolved skin, but just a few days in psoriatic skin lesions. Furthermore, angiogenic factors produced by epidermal keratinocytes promote abnormal dermal vascular proliferation and facilitate cutaneous infiltrate of inflammatory cells. Consequently, a stratum corneum forms from differentiated, hyperproliferative keratinocytes manifesting clinically as red, scaly lesions, which occur most commonly in predilective areas for psoriasis, such as knees, elbows and the scalp; however, the process may involve any part of the skin as well as finger- and toenails.

The understanding of the immune dysregulation that triggers the inflammatory cascade in psoriasis, has greatly improved over the past 20 years. Genetic and environmental factors play an important role in the development of the disease; it is suggested that stress factors, such as skin damage or bacterial infection can stimulate keratinocytes to release antimicrobial peptide LL-37 (cathelicidin). Cathelicidin binds subsequently to either bacterial DNA or the DNA of the patient, forming the complex that activates Toll-like receptor 9 (TLR9) on the surface of dendritic cells $[6,7]$ as well as directly stimulates T lymphocytes [8]. After migrating to the local lymph nodes, dendritic cells release tumor necrosis factor $\alpha$ (TNF- $\alpha$ ) and interleukins 12 and 23. Elevated concentration of

Address for correspondence: Barbara Olszewska MD, Department of Dermatology, Poznan University of Medical Sciences, 49 Przybyszewskiego St, 60-355 Poznan, Poland, phone: +48 505039 253, e-mail: b.olszewska@gumed.edu.pl Received: 2.10.2017, accepted: 26.11.2017. 
theseproximal inducers leads to proliferation of Th1, Th17 Th22 lymphocytes and induction of interleukins IL-17 and IL-22. Interleukin 17 produces a chemotactic gradient for the migration of inflammatory cells to the epidermis and together with IL-22 delays normal differentiation of keratinocytes, which contributes to its hyperproliferation [9].

\section{Biological treatment of psoriasis}

Due to distinctive pathological mechanisms leading to the formation of psoriatic lesions, in which the crucial role is played by the cell-mediated immune response, the advent of medications specifically modulating the adaptive immune response has become a milestone in treatment of moderate and severe psoriasis. Biological agents include fusion proteins and monoclonal antibodies, which are designed to target specific components of the immune system, usually by binding the mediators of inflammation or their respective receptors. High selectivity of targeted immunotherapy minimalizes the risk of adverse effects and enhances the effectiveness of treatment.

The European market currently has eight biological drugs available for treatment of psoriasis, six of them infliximab, adalimumab, golimumab, ustekinumab, secukinumab and ixekizumab - being structurally monoclonal antibodies. As for the remaining two, etanercept is a fusion protein and apremilast has the structure of a small molecule. Four of those biologicals (infliximab, etanercept, adalimumab and golimumab) directly inhibit activity of TNF- $\alpha$, whereas ustekinumab, secukinumab and ixekizumab target interleukin-mediated signaling pathways by inhibition of IL-12/23 (binding to their common p40 subunit) and IL-17. Apremilast is a selective inhibitor of phosphodiesterase IV and, through the inhibition of CAMP degradation, lowers the expression of both TNF- $\alpha$ and interleukins 23 and 17. Certolizumab pegol, a fusion protein inhibiting TNF- $\alpha$, is registered in the European Union for the treatment of psoriatic arthritis (Table 1 ).

\section{Loss of effectiveness of biological drugs}

Though biological therapy had revolutionized the treatment of moderate to severe forms of psoriasis, it seems that it had not exactly lived up to its expectations. The most common causes of discontinuation of biological treatment are initial lack of effectiveness or loss thereof over time. Assuming a 75\% reduction in the PASI score (PASI-75) as an indicator of adequate response, in an observational study carried out by Esposito et al. to estimate the long-term survival rate of anti-TNF- $\alpha$ therapy in a cohort of 650 patients, primary lack of efficacy has been observed in $5 \%(n=35)$ of patients treated with TNF- $\alpha$ inhibitors, and treatment discontinuation due to secondary inefficacy has been reported subsequently in $14 \%(n=94)$ of patients [10]. In other studies the number of patients responding adequately to the administered treatment had decreased by $11 \%$ between the $24^{\text {th }}$ and $108^{\text {th }}$ weeks of therapy in patients treated with adalimumab [11], by $12 \%$ between the $48^{\text {th }}$ and $96^{\text {th }}$ weeks of therapy in patients treated with etanercept [12] and by $23 \%$ between the $10^{\text {th }}$ and $50^{\text {th }}$ weeks of therapy in patients treated with infliximab [13]. The main suspected reasons for the reduced efficacy of the biological treatment include the development of anti-drug antibodies, the presence of gene polymorphisms that determine response to treatment and the change in proportions of cytokines involved in the inflammatory process during the course of illness [14].

Results of the multicentre, prospective, observational PSOLAR study, conducted between 2007 and 2013, confirm previous findings - the main reason for discontinuation of treatment with biological drugs is loss of its efficacy over time. The study included approximately 12000 patients receiving treatment with systemic therapies for psoriasis, or eligible to receive such treatment, and whose percent of the body surface area affected by psoriatic lesions specified by the body surface area (BSA) varied from 18.2 to 27.9. Patients had been given ustekinumab, infliximab, adalimumab and/or etanercept as first-, second- or third-line therapy - cohorts within each line of therapy were then analyzed independently. For first-line users who then discontinued the therapy, the median duration of treatment was 676 days for infliximab, 613 days for ustekinumab, 569 days for adalimumab and 565 days for etanercept [15]. In the group of patients who had been previously treated with biological drugs and were subsequently receiving second-line treatment, the median duration of treatment was 621 days for ustekinumab, 510 days for adalimumab, 446 days for infliximab and 317 days for etanercept, whereas for third-line therapy the corresponding duration was 592, 457, 416 and 337 days for ustekinumab, adalimumab, infliximab and etanercept, respectively. In $10.6 \%$ of patients included in the PSOLAR study, who were given biologicals as the first-line treatment, a concurrent diagnosis of psoriatic arthritis had been reported, while the corresponding figure for the group of patients receiving second-line treatment was $13.4 \%$, and for the group of patients receiving biological treatment as a third-line therapy $-15.3 \%$. There was no statistically significant difference found in the drug survival rate in the group of patients with concomitant psoriatic arthritis.

It might also be worth mentioning that drug survival of ustekinumab was significantly better than that of TNF- $\alpha$ inhibitors as only $8.6 \%$ of patients receiving ustekinumab as the first-line treatment had discontinued the therapy, when corresponding proportions for TNF- $\alpha$ inhibitors were $25.4 \%$ for infliximab, $37.6 \%$ for adalimumab and $43.9 \%$ for etanercept, and these trends were similar for second-line and third-line therapies. This observation appears very much in line with the results of 
Table 1. Biological drugs registered in the European Union for the treatment of psoriasis and psoriatic arthritis

\begin{tabular}{|c|c|c|c|c|}
\hline Name & Structure & Mechanism of function & Dosing & Indications \\
\hline $\begin{array}{l}\text { Infliximab (Remicade, } \\
\text { biosimilars: Inflectra, } \\
\text { Remsima) }\end{array}$ & $\begin{array}{l}\text { Chimeric human-mouse } \\
\text { monoclonal IgG antibody }\end{array}$ & $\begin{array}{l}\text { Binds to soluble } \\
\text { and transmembrane } \\
\text { form of TNF- } \alpha\end{array}$ & $\begin{array}{c}5 \mathrm{mg} / \mathrm{kg} \text { intravenously } \\
\text { at } 0,2 \text {, and } \\
6 \text { weeks followed by } \\
\text { a maintenance regimen } \\
\text { of } 5 \mathrm{mg} / \mathrm{kg} \text { i.v. every } \\
8 \text { weeks }\end{array}$ & Psoriasis/PsA \\
\hline $\begin{array}{l}\text { Etanercept (Enbrel, } \\
\text { biosimilar: Benepali) }\end{array}$ & $\begin{array}{l}\text { Fusion protein consisting } \\
\text { of the extracellular } \\
\text { portion of the tumor } \\
\text { necrosis factor receptor } \\
\text { (TNFR) linked to the Fc } \\
\text { portion of human IgG1 }\end{array}$ & $\begin{array}{l}\text { Binds to soluble } \\
\text { form of TNF- } \alpha\end{array}$ & $\begin{array}{c}50 \mathrm{mg}(0.8 \mathrm{mg} / \mathrm{kg} \text { in } \\
\text { children) subcutaneously } \\
\text { once weekly; in psoriasis } \\
\text { a dosage of } 25 \mathrm{mg} \\
\text { twice weekly can be } \\
\text { administered }\end{array}$ & Psoriasis/PsA \\
\hline Adalimumab (Humira) & $\begin{array}{l}\text { Human monoclonal IgG } \\
\text { antibody }\end{array}$ & $\begin{array}{l}\text { Inhibits TNF- } \alpha \text { by } \\
\text { occupying the TNF- } \alpha \\
\text { receptor-binding site }\end{array}$ & $\begin{array}{l}40 \mathrm{mg} \text { subcutaneously } \\
\text { every } 2 \text { weeks; in PsA the } \\
\text { initial dose is } 80 \mathrm{mg}\end{array}$ & Psoriasis/PsA \\
\hline Ustekinumab (Stelara) & $\begin{array}{l}\text { Human monoclonal lgG } \\
\text { antibody }\end{array}$ & $\begin{array}{l}\text { Binds to } p 40 \text { subunit } \\
\text { common to IL-12 and } \\
\text { IL-23 }\end{array}$ & $\begin{array}{c}45 \text { mg subcutaneously, } \\
\text { next dose after } 4 \text { weeks } \\
\text { and then once every } \\
12 \text { weeks }\end{array}$ & Psoriasis \\
\hline Golimumab (Simponi) & $\begin{array}{l}\text { Human monoclonal IgG } \\
\text { antibody }\end{array}$ & $\begin{array}{l}\text { Binds to soluble } \\
\text { and transmembrane } \\
\text { form of TNF- } \alpha\end{array}$ & $\begin{array}{l}50 \text { mg subcutaneously, } \\
\text { once monthly }\end{array}$ & PsA \\
\hline $\begin{array}{l}\text { Certolizumab Pegol } \\
\text { (Cimzia) }\end{array}$ & $\begin{array}{l}\text { Fusion protein consisting } \\
\text { of humanized Fab } \\
\text { subunit of the antibody } \\
\text { and polyethylenglycol }\end{array}$ & $\begin{array}{l}\text { Binds to soluble } \\
\text { and transmembrane } \\
\text { form of TNF- } \alpha\end{array}$ & $\begin{array}{l}400 \text { mg subcutaneously } \\
\text { at } 0,2,4 \text { weeks, followed } \\
\text { by } 200 \text { mg every } 2 \text { weeks }\end{array}$ & PsA \\
\hline Secukinumab (Cosentyx) & $\begin{array}{l}\text { Human monoclonal IgG } \\
\text { antibody }\end{array}$ & Binds to IL-17A & $\begin{array}{c}300 \text { mg subcutaneously } \\
\text { once weekly for } 5 \text { weeks, } \\
\text { followed by } 300 \text { mg every } \\
4 \text { weeks }\end{array}$ & Psoriasis/PsA \\
\hline Ixekizumab (Taltz) & $\begin{array}{l}\text { Humanized monoclonal } \\
\text { lgG4 antibody }\end{array}$ & Binds to IL-17A & $\begin{array}{l}160 \text { mg subcutaneously } \\
\text { followed by } 80 \text { mg at } 2 \text {, } \\
4,6,8,10 \text { and } 12 \text { weeks; } \\
\text { maintenance regimen of } \\
80 \text { mg every } 4 \text { weeks }\end{array}$ & Psoriasis/PsA \\
\hline Apremilast (Otezla) & Small molecule & $\begin{array}{l}\text { Phosphodiesterase } 4 \\
\text { (PDE4) inhibitor }\end{array}$ & 30 mg orally twice daily & Psoriasis/PsA \\
\hline
\end{tabular}

Source: prepared by authors based on data provided by manufacturers.

the BADBIR study, which included 3523 patients receiving ustekinumab, infliximab, adalimumab or etanercept as the first-line treatment [16]. The decline in drug survival observed within all treatment cohorts among patients receiving second- and third-line therapies in comparison with patients receiving biological treatment for the first time suggests that prior therapy with biologicals is a negative prognostic factor for drug survival and effectiveness of second- and third-line treatments.

\section{Immunogenicity}

All instances of direct introduction of protein molecules into the bloodstream, including use of biotechnology-derived therapeutic monoclonal antibodies, have potential to induce an acquired immune response directed against the foreign protein. Antibodies directed against the drugs (anti-drug antibodies - ADA) can be developed in a pathway dependent or independent of T lymphocytes, and their presence has been shown to be associated with lower serum drug levels and consequent loss of clinical efficacy and increases the incidence of adverse drug reactions. The involvement of ADA in lowering of drug survival has been confirmed in infliximab [17] and adalimumab [18].

Possible means of reduction of potential immunogenicity during the stage of development of therapeutic proteins are humanization of antibodies, higher stringency in production resulting in increased purity of the product, correct storage of the product to avoid formation of protein aggregates, identifying potential lymphocyte epitopes within the molecular structure of the drug 
in silico; another viable strategy is depletion of B and Th-cell epitopes as well as adding epitopes of regulatory T cells (Tregitopes), but using that technique carries a risk of forming a generation of new potentially immunogenic epitopes. It is also suggested that alternative routes of drug administration (e.g. transmucosal) can lower the immunogenicity by induction of peripheral tolerance mediated by dendritic cells and Treg lymphocytes. Therapy-related factors that can reduce the possibility of inducing immunological response against biological drugs include increasing the frequency of administration, use of maintenance therapy, avoiding intermittent drug administration, avoiding treatment with suboptimal doses, and concomitant use of immunosuppressive drugs, e.g. methotrexate or azathioprine, preferably at the lowest recommended dose. It would seem advisable to precede introducing of a biological drug with an immunosuppressive therapy because ADAs can form at the onset of treatment $[19,20]$. Of note, in the large-scale PSOLAR study, concomitant use of methotrexate and biological treatment in a cohort of biologically-naive patients was independently associated with a shorter time to discontinuation of therapy compared with no use of methotrexate [15]. This correlation has not been observed in groups of patients receiving second- and third-line biological therapy and its clinical relevance is yet unknown.

\section{Gene polymorphisms}

Analyses of the genome of psoriatic patients suggest that there are genetic factors underlying individual response to biological treatment. Currently, attempts are being made to identify gene polymorphisms linked to the mechanisms of resistance to biological therapy, in order to design tailored treatment options and ways to individualize qualification for biological therapy. Although the majority of genes identified as susceptibility genes for psoriasis encode proinflammatory factors such as IL-17, IL-12B, IL-23R, HLA Cw6, at the same time genome-wide studies have detected single nucleotide polymorphisms (SNP) on candidate genes for the disease susceptibility that do not appear to be linked directly to pathogenesis of psoriasis. Most recent clinical findings indicate the presence of over 80 SNPs localized on seven genes, which have been reported to be associated with the response to anti-TNF- $\alpha$ treatment (concerning adalimumab and infliximab) [21].

A statistical relationship has been also confirmed between the single nucleotide polymorphism in a gene encoding CD84 (rs6427528) and response to treatment with fusion protein etanercept. The presence of the heterozygous variant (versus homozygous) of the above-mentioned gene is linked with a better therapeutic response to etanercept.

There also seems to be evidence supporting the role of gene polymorphisms in the genes IL12B (rs3213094) and TNFAIP3 (rs610604) influencing response to treatment with ustekinumab - patients with the cw6+/IL12B variant seem to have a more favourable response in comparison to patients with the cw6-/IL12B1 variant [22].

Identifying single nucleotide polymorphisms with potential of serving as both positive and negative predictors of treatment response to biological therapies elicits hope for developing genetic tests useful in clinical practice that would facilitate development of novel and more effective targeted therapies.

\section{IL-17 and IL-23 inhibitors}

To date, in the European Union, there have been two monoclonal antibodies targeting IL-17 pathway approved for clinical use - secukinumab and ixekizumab, in addition to one biological agent - ustekinumab - its mechanism of action being inhibition of interleukins 12 and 23 by binding to their common p40 subunit.

Currently, in the phase of clinical trials, there are three novel therapeutic agents being selective antagonists of interleukin 23 in a mechanism of inhibition of its p19-subunit, which brings hopes for increased selectivity and safety of treatment, as compared to inhibition of p40 subunit. Guselkumab is a human monoclonal IgG1 antibody directed against p19-subunit of IL-23A. In phase III, multicenter, randomized VOYAGE 2 study including 992 psoriatic patients, guselkumab was proven to be more efficient than the TNF- $\alpha$ inhibitor adalimumab - PASI 75 response was achieved in $89.1 \%$ of patients treated with guselkumab in comparison to $71 \%$ of patients receiving adalimumab. Additionally, $44.2 \%$ of patients treated with guselkumab reached PASI 100 while an identical response could be achieved in only $26.6 \%$ of patients receiving adalimumab [23]. Another investigational interleukin-23 p-19 subunit inhibitor is a humanized, monoclonal IgG1 antibody tildrakizumab. In phase III reSURFACE 1 and reSURFACE 2 trials, PASI 90 improvement rates with the use of tildrakizumab were approaching $60 \%$ in patients with moderate to severe plaque psoriasis at week 28 [24]. The next human IgG monoclonal antibody with a similar mode of action is risankizumab. In a clinical phase I study, 87\% of patients with moderate to severe plaque psoriasis have achieved PASI 75 in 12 weeks, while $58 \%$ of participants have reached PASI 90 in the same time frame. Additionally, a reduction in expression of lesional skin genes associated with IL-23/IL-17 signaling pathways and normalization of psoriatic lesion gene expression profiles was confirmed and changes at the molecular level were positively correlated with improvement of PASI [25].

\section{Biosimilars}

During the last decade, the development of biological drugs has improved results of treatment of many autoimmune diseases, but availability of such therapies is 
usually restricted to cases where previously administered systemic therapies have shown no effect. One of the main limiting features of biological therapy is the high cost of treatment, including not only the price of the biological drug itself, but also costs related to qualification for the treatment and hospitalization. In order to provide greater access to biologicals for psoriatic patients, efforts are being made to develop safe and effective biosimilar agents. Biosimilar drugs are medicines biologically and structurally similar to an already registered biological drug, with no clinically meaningful differences in purity, efficacy or safety of treatment [26]. Biosimilar drugs are thus different to generic medications because a generic drug, by definition, is an exact copy of its reference medicine and must have the same chemical structure. This condition is not achievable for complex, high molecular weight protein molecules for technical reasons, and so biosimilar drugs cannot be structurally identical to the original product.

The possibility of treatment of psoriasis vulgaris and psoriatic arthritis with biosimilar monoclonal antibodies has been introduced in the European Union relatively recently. In 2013, EMA approved the first biosimilar CT-P13, being an equivalent of TNF- $\alpha$ inhibitor infliximab. Because patent rights for the original medication expired in most of European countries in January 2015, CT-P13 has been available in Europe since January 2016 under the names of Inflectra and Remsima. In 2015, EMA also approved SB4, a biosimilar drug for etanercept. Patent rights for the original product expired in January 2015, and subsequently the drug was authorized for marketing in the European Union under the name of Benepali. Another biosimilar drug accepted by EMA for review in July 2016 is SB5, an equivalent drug to adalimumab. Since the patent rights for the original product, sold under the name of Humira, are going to expire in most European countries in April 2018, availability of this product on the EU market is to be expected in the upcoming years.

Despite many opportunities emerging due to increased availability of biosimilar medications, replacing the reference biological drugs with biosimilars remains a contentious issue. Particular attention is being paid to the possible immunogenicity of biosimilar drugs. However, recent clinical reports do not confirm increased immunogenicity of biosimilar drugs compared to their respective original products. Efficacy and immunogenicity of Remsima in comparison to the original product Remicade has been evaluated in phase I PLANETAS study, including patients with ankylosing spondylitis, and in phase III PLANETRA study including patients with rheumatoid arthritis. No statistically significant differences were observed with regard to immunogenicity, efficacy and occurrence of adverse effects $[27,28]$. Anti-drug antibodies have been detected in $48.4 \%$ of patients treated with the biosimilar and in $48.2 \%$ of patients treated with the reference product. Phase III PLANETRA study has given comparable results in terms of effectiveness and safety, however the anti-drug antibodies were less frequently identified in patients receiving the biosimilar product in $0.7 \%$ in comparison to $13.1 \%$ of patients treated with etanercept [29]. On the basis of the above-mentioned research, biosimilars of infliximab have been authorized for marketing in the European Union for the same indications as their reference product, including psoriasis and psoriatic arthritis.

\section{Combined biological therapy}

Because the main factor underlying the pathogenesis of psoriasis is dysfunction of many cytokine pathways, and some patients treated with biological drugs do not respond adequately to therapy, it seems that in some cases the drug directed against just one cytokine might not be sufficient to contain the disease. However, there is not much clinical data to be found regarding combined treatment with two biological agents, because in the majority of patients, adequate clinical response can be achieved with a single biological drug and addition of another biological can cause concerns for potential increase in side effects. Isolated cases of combined therapy with etanercept and ustekinumab [30], etanercept and infliximab [31] and apremilast with ustekinumab, adalimumab, certolizumab, infliximab and golimumab [32] have been reported in patients with severe, refractory psoriasis with concomitant psoriatic arthritis, whereby the treatment administered had resulted in significant skin and joint improvement. The main adverse effects described were nausea and diarrhea and no serious adverse effects had been reported. To date however, there have been no long-term, prospective studies including large cohorts of patients, which would assess the efficacy and safety of combined biological therapy and this approach is not recommended in current guidelines for psoriasis and PsA. No cases of treatment with two monoclonal antibodies have thus far been reported in the literature.

A hope for the long-awaited revolution in the current approach to biological treatment of psoriasis and psoriatic arthritis lies in the possible introduction of bispecific monoclonal antibodies. Bispecific agents are antibodies composed of Fab subunits of two different monoclonal antibodies, directed against different molecular targets [33]. The concept of creating an antibody that would be able to inhibit two different cytokines simultaneously is not a new one, it was first introduced 30 years ago, but similar agents have not found any use in the past due to their strong immunogenicity and increased risk of major side effects [34]. Progress that has since been made in the field of molecular engineering and better understanding of cellular receptor biology has though led to the development of a new generation of such drugs. There are currently seven potential bispecific therapeutic antibodies under development, the main cytokine 
targeted being IL-17. The potential advantages of therapy with bispecific antibodies are more efficient and selective inhibition of inflammatory paths and reduced risk of changing the proportion of cytokines involved in the inflammatory process as a response to treatment [35]. Combined inhibition of IL-17 and TNF- $\alpha$ could turn out to be particularly beneficial because both of those factors induce synergistically some of the genes playing a role in the pathogenesis of psoriasis [36]. Before including bispecific antibodies in the arsenal of agents for the treatment of psoriasis and psoriatic arthritis, it is however necessary to conduct long-term studies due to possible dangers related to an excessive inhibition of the host immune response.

\section{Conclusions}

Whilst biological systemic therapies have revolutionized the treatment of psoriasis and psoriatic arthritis, and, after a decade of experience, the outlook is generally positive, they are not flawless. The main barriers in psoriasis biological therapy are the high costs of biological treatment, potential severe adverse effects of long-term therapy and loss of its effectiveness over time. Mechanisms of loss of efficacy can be related not only to the formation of specific anti-drug antibodies, but can also be a result of genotype differences. Means of prevention of development of antibodies directed against biological drugs are strict adherence to the dosing regiments and concomitant use of classic immunosuppressive agents. Research on the influence of single nucleotide polymorphisms on the treatment of psoriasis provides hope for introduction of potential genetic tests and development of more individually targeted therapies. The future of biological therapy is novel monoclonal antibodies targeting IL-17 and IL-23, which in clinical studies have been proven to be more efficient and less immunogenic than TNF- $\alpha$ inhibitors. In early phases of clinical studies are bispecific antibodies targeting two different cytokines. Potential reduction in treatment costs by a third can be achieved by the introduction of biosimilar drugs to clinical practice, which would consequently grant access to biological treatment to increasing numbers of patients.

\section{Conflict of interest}

The authors declare no conflict interest.

\section{References}

1. Julia A, Tortosa R, Hernanz JM. Risk variants for psoriasis vulgaris in a large case-control collection and association with clinical subphenotypes. Hum Mol Genet 2012; 21: 4549-57.

2. Łakuta P, Marcinkiewicz K, Bergler-Czop B, BrzezińskaWcisło L. How does stigma affect people with psoriasis? Adv Dermatol Allergol 2017; 34: 36-41.
3. Chandran V, Raychaudhuri SP. Geoepidemiology and environmental factors of psoriasis and psoriatic arthritis. J Autoimmun 2010; 34: 314-21.

4. Ibrahim G, Waxman R, Helliwell PS. The prevalence of psoriatic arthritis in people with psoriasis. Arthritis Rheum 2009; 61: 1373-8.

5. Zhou X, Krueger JG, Kao MC, et al. Novel mechanisms of Tcell and dendritic cell activation revealed by profiling of psoriasis on the 63,100-element oligonucleotide array. Physiol Genomics 2003; 13: 69-78.

6. Gilliet M, Lande R. Antimicrobial peptides and self-DNA in autoimmune skin inflammation. Curr Opin Immunol 2008; 20: 401-7

7. Zabłotna M, Sobjanek M, Purzycka-Bohdan D, et al. The significance of Toll-like receptor (TLR) 2 and 9 gene polymorphisms in psoriasis. Adv Dermatol Allergol 2017; 34: 85-6.

8. Lande R, Botti E, Jandus C. The antimicrobial peptide LL37 is a T-cell autoantigen in psoriasis. Nat Commun 2014; 5: 5621.

9. Prieto-Pérez R, Cabaleiro T, Daudén E, et al. Genetics of psoriasis and pharmacogenetics of biological drugs. Autoimmune Dis 2013; 2013: 613086.

10. Esposito M, Gisondi P, Cassano N, et al. Survival rate of antitumour necrosis factor-alpha treatments for psoriasis in routine dermatological practice: a multicentre observational study. Br J Dermatol 2013; 169: 666-72.

11. Papp K, Menter A, Poulin Y, et al. Long-term outcomes of interruption and retreatment vs. continuous therapy with adalimumab for psoriasis: subanalysis of REVEAL and the open-label extension study. J Eur Acad Dermatol Venereol 2013; 27: 634-42.

12. Tyring S, Gordon KB, Poulin Y, et al. Long-term safety and efficacy of $50 \mathrm{mg}$ of etanercept twice weekly in patients with psoriasis. Arch Dermatol 2007; 143: 719-26.

13. Menter A, Feldman SR, Weinstein GD, et al. A randomized comparison of continuous vs. intermittent infliximab maintenance regimens over 1 year in the treatment of moderateto-severe plaque psoriasis. J Am Acad Dermatol 2007; 56: 31.e1-15.

14. Kui R, Gál B, Gaál M, et al. Presence of antidrug antibodies correlates inversely with the plasma tumor necrosis factor (TNF)-alpha level and the efficacy of TNF-inhibitor therapy in psoriasis. J Dermatol 2016; 43: 1018-23.

15. Menter A, Papp KA, Gooderham M, et al. Drug survival of biologic therapy in a large, disease-based registry of patients with psoriasis: results from the Psoriasis Longitudinal Assessment and Registry (PSOLAR). J Eur Acad Dermatol Venereol 2016; 30: 1148-58.

16. Warren RB, Smith CH, Yiu ZZ, et al. Differential drug survival of biologic therapies for the treatment of psoriasis: a prospective observational cohort study from the British Association of Dermatologists Biologic Interventions Register (BADBIR). J Invest Dermatol 2015; 135: 2632-40.

17. Hanauer SB, Wagner CL, Bala M, et al. Incidence and importance of antibody responses to infliximab after maintenance or episodic treatment in Crohn's disease. Clin Gastroenterol Hepatol 2004; 2: 542-53.

18. Lecluse LA, Driessen RJ, Spuls PI, et al. Extent and clinical consequences of antibody formation against adalimumab in patients with plaque psoriasis. Arch Dermatol 2010; 146: 127-32.

19. Vincent T, Best M, Plawecki M, Girard C. Complete reversion of anti-infliximab immunization by methotrexate combination in a patient with psoriasis. J Dermatol 2015; 42: 1030-1. 
20. Mrowietz U, de Jong EM, Kragballe K, et al. A consensus report on appropriate treatment optimization and transitioning in the management of moderate-to-severe plaque psoriasis. J Eur Acad Dermatol Venereol 2014; 28: 438-53.

21. Nishikawa R, Nagai H, Bito T, et al. Genetic prediction of the effectiveness of biologics for psoriasis treatment. J Dermatol 2016; 43: 1273-7.

22. Galluzzo M, Boca AN, Botti E, et al. IL12B (p40) gene polymorphisms contribute to ustekinumab response prediction in psoriasis. Dermatology 2016; 232: 230-6.

23. Blauvelt A, Papp KA, Griffiths CE, et al. Efficacy and safety of guselkumab, an anti-interleukin-23 monoclonal antibody, compared with adalimumab for the continuous treatment of patients with moderate to severe psoriasis: results from the phase III, double-blinded, placebo- and active comparator-controlled VOYAGE 1 trial. J Am Acad Dermatol 2017; 76: 405-17.

24. https://www.almirall.pl/pl/media/komunikaty-prasowe/ media-detail-new?title=data-from-tildrakizumab-clinicaldevelopment-program-presented-at-the-2017-americanacademy-of-dermatology-meeti-1\&articleld=858888 (access: 04.04.2017)

25. Krueger JG, Ferris LK, Menter A, et al. Anti-IL-23A mAb BI 655066 for treatment of moderate-to-severe psoriasis: safety, efficacy, pharmacokinetics, and biomarker results of a single-rising-dose, randomized, double-blind, placebocontrolled trial. J Allergy Clin Immunol 2015; 136: 116-24.e117.

26. Teresiak-Mikołajczak E, Osmola-Mańkowska A, Adamski Z, Kaszuba A. Biologiczne leki biopodobne (biosmilary) w dermatologii - szansa na lepszą dostępność leczenia. Dermatol Prakt 2016; 2.

27. Yoo DH, Hrycaj P, Miranda P, et al. A randomised, doubleblind, paralel-group study to demonstrate equivalence in efficacy and safety of CT-P13 compared with innovator infliximab when coadministered with methotrexate in patients with active rheumatoid arthritis: the PLANETRA study. Ann Rheum Dis 2013; 72: 1613-20.

28. Park W, Hrycaj P, Jeka S, et al. A randomised, double-blind, multicentre, paralel-group, prospective study comparing the pharmacokinetics, safety and efficacy of CT-P13 and innovator infliximab in patients with ankylosing spondylitis: the PLANETAS study. Ann Rheum Dis 2013; 71: 1605-12.

29. Emery P, Vencovský J, Sylwestrzak A, et al. A phase III randomised, double-blind, parallel-group study comparing SB4 with etanercept reference product in patients with active rheumatoid arthritis despite methotrexate therapy. Ann Rheum Dis 2017; 76: 51-7.

30. Cuchacovich R, Garcia-Valladares I, Espinoza LR. Combination biologic treatment of refractory psoriasis and psoriatic arthritis. J Rheumatol 2012; 39: 187-93.

31. Hamilton TK. Treatment of psoriatic arthritis and recalcitrant skin disease with combination therapy. J Drugs Dermatol 2008; 7: 1089-93.

32. Metyas S, Messiah R, Gettas T, et al. Combination therapy of apremilast and biologic agent as a safe option of psoriatic arthritis and psoriasis. Arthritis Rheumatol 2016; 68 (Suppl 10): abs. 1725.

33. Tiller KE, Tessier PM. Advances in antibody design. Annu Rev Biomed Eng 2015; 17: 191-216.

34. Muller D, Kontermann RE. Bispecific antibodies for cancer immunotherapy: current perspectives. BioDrugs 2010; 24: 89-98.
35. Torres T, Romanelli M, Chiricozzi A. A revolutionary therapeutic approach for psoriasis: bispecific biological agents. Expert Opin Investig Drugs 2016; 25: 751-4.

36. Chiricozzi A, Guttman-Yassky E, Suárez-Farińas M, et al. Integrative responses to IL-17 and TNF-alpha in human keratinocytes account for key inflammatory pathogenic circuits in psoriasis. J Invest Dermatol 2011; 131: 677-87. 